\title{
Genetic parameters for residual feed intake in a random population of Pekin duck
}

\author{
Yunsheng Zhang ${ }^{1,2}$, Zhan Bao Guo ${ }^{2}$, Ming Xie ${ }^{2}$, Zhiying Zhang ${ }^{1, *}$, and Shuisheng Hou ${ }^{2, *}$
}

* Corresponding Authors: Zhiying Zhang Tel: +86-10-62816009, Fax: +86-10-62816009,

E-mail: zhangzhy@nwsuaf.edu.cn

Shuisheng Hou

Tel: +86-10-62815832, Fax: +86-10-62815832,

E-mail: houss@263.net

${ }^{1}$ College of Animal Science and Technology, Northwest A\&F University, Yangling, Shaanxi 712100, China

${ }^{2}$ Institute of Animal Sciences, Chinese Academy of

Agricultural Sciences, Beijing 100193, China

Submitted Jul 7, 2015; Revised Aug 24, 2015; Accepted Mar 25, 2016
Objective: The feed intake (FI) and feed efficiency are economically important traits in ducks. To obtain insight into this economically important trait, we designed an experiment based on the residual feed intake (RFI) and feed conversion ratio (FCR) of a random population Pekin duck.

Methods: Two thousand and twenty pedigreed random population Pekin ducks were established from 90 males mated to 450 females in two hatches. Traits analyzed in the study were body weight at the 42th day (BW42), 15 to 42 days average daily gain (ADG), 15 to 42 days FI, 15 to 42 days FCR, and 15 to 42 days RFI to assess their genetic interrelationships. The genetic parameters for feed efficiency traits were estimated using restricted maximum likelihood (REML) methodology applied to a sire-dam model for all traits using the ASREML software.

Results: Estimates heritability of BW42, ADG, FI, FCR, and RFI were 0.39, 0.38, 0.33, 0.38, and 0.41 , respectively. The genetic correlation was high between RFI and FI (0.77) and moderate between RFI and FCR (0.54). The genetic correlation was high and moderate between FCR and ADG (-0.80), and between FCR and BW42 (-0.64), and between FCR and FI (0.49), respectively.

Conclusion: Thus, selection on RFI was expected to improve feed efficiency, and reduce FI. Selection on RFI thus improves the feed efficiency of animals without impairing their FI and increase growth rate.

Keywords: Genetic Parameters, Residual Feed Intake, Pekin Duck

\section{INTRODUCTION}

Feed costs contribute a major portion to the total cost of livestock production. Improvement in feed efficiency would reduce the amount of feed required for growth, the production cost and the amount of nitrogenous waste. Feed efficiency is usually expressed as the amount of feed intake (FI) per body weight gain (BWG), which is also known as feed conversion ratio (FCR). Feed efficiency has traditionally been improved through selection for decreased FI and increased growth. Feed efficiency is difficult to measure with high labor and equipment costs because the ducks are raised in groups on the floor. But an improvement in feed efficiency is important because it may reduce the production costs in ducks, lower their feed requirements for growth was well decreasing nitrogenous waste production [1].

Koch et al. [2] was the first to introduce the concept of adjusting FI for performance traits with the intention of evaluating different measures of efficiency on indirect feed utilization and efficiency. Residual feed intake (RFI) is defined as the difference between observed feed intake and predicted feed intake based on estimates of maintenance and production requirements. Animals that require less feed than expected for maintenance and production purposes 
have a negative RFI value and are desirable in animal production as they reduce feed costs and improve profitability of production. This trait was first investigated in poultry for the laying hen [3], and thereafter more commonly in mammals including; cattle [4], pigs [5,6], and rabbits [7].

Genetic variability in RFI has been investigated in chickens [8], beef cattle [9-13], and pigs $[5,6,14,15]$. To date, there are no studies on RFI heritabilities and genetic correlation between RFI and FCR in Pekin ducks.

The objectives of this study were to estimate genetic parameters for RFI, FCR, average daily gain (ADG), BW42 and FI in a Pekin duck population, and to ascertain the genetic relationships among the traits studied in Pekin ducks.

\section{MATERIALS AND METHODS}

\section{Experimental population and animal husbandry}

The care and use of all ducks in this experiment were approved by the Animal Care and Use Committee of the Institute of Animal Sciences, Chinese Academy of Agricultural Science (CAAS). The study included a total of 2,020 Pekin ducks from a random mating population which was raised in the Institute of Animal Science, CAAS. These ducks were pedigreed by mating 90 males with 450 female in two hatches between April 2014 and May 2014. In the first two weeks, ducks were placed in pens $(0.08 \mathrm{~m} 2 /$ bird $)$. All ducks were fasted for 12 hours at 14th day of the experiment and transferred to their individual metabolic cages with a dimension of $50 \mathrm{~cm}$ (width) $\times 50 \mathrm{~cm}$ (length) $\times 30 \mathrm{~cm}$ (height) at the same day where they remained caged until 42 days of age. During the first three days after hatching, lighting was continuous $24 \mathrm{~L}: 0 \mathrm{D}$ (that is to say $24 \mathrm{~h}$ of light and $0 \mathrm{~h}$ of dark); then the lighting regimen of $20 \mathrm{~L}: 4 \mathrm{D}$ was assigned to the ducks from 4 days to 42 days. Ingredient composition and chemical composition of feedstuffs used in this study is presented in Table 1.

\section{Traits under the study and statistical analysis}

Body weight was recorded at the beginning ( 15 days old) and the end ( 42 days old) of the test, and the BWG and the ADG were computed for the test period. Traits analyzed in the study were body weight at the 42 th day, metabolic body weight at the 42th day (BW42 ${ }^{0.75}$ ), 15 to 42 days ADG, 15 to 42 days FI, 15 to 42 days FCR, and 15 to 42 days RFI to assess their genetic inter-relationships. FCR was calculated as FI divided by BWG. RFI was calculated according to Aggrey et al. [8] (2010), RFI $=$ FI- $\left(\mathrm{a}+\mathrm{b}_{1} \times \mathrm{BW}_{42} 2^{0.75}+\mathrm{b}_{2} \times \mathrm{BWG}\right)$.

Where " $\mathrm{a}$ " is the intercept and b1 and b2 are of partial regression coefficients of FI on BW42 $2^{0.75}$ and BWG, respectively. RFI values were obtained using the PROC REG procedure in SAS software package [16].

The genetic parameters for feed efficiency traits were estimated using restricted maximum likelihood (REML) methodology
Table 1. The proportion of ingredients and their chemical compositions in feeds used to feed Pekin ducks from day 1 to 42

\begin{tabular}{lcc}
\hline Items & $\begin{array}{c}\text { Stage } 1 \\
(\mathbf{0} \text { to } 14 \mathrm{~d})\end{array}$ & $\begin{array}{c}\text { Stage 2 } \\
(\mathbf{1 5} \text { to } \mathbf{4 2} \mathrm{d})\end{array}$ \\
\hline Ingredient & & \\
$\quad$ Corn (\%) & 58.23 & 59.22 \\
Wheat bran (\%) & & 11.94 \\
Soybean meal (\%) & 36.17 & 25.32 \\
Soybean oil (\%) & 2.03 & \\
Limestone (\%) & 1.20 & 1.20 \\
Dicalcium phosphate (\%) & 1.40 & 1.40 \\
Sodium chloride (\%) & 0.30 & 0.30 \\
DL-Methionine (\%) & 0.17 & 0.12 \\
Vitamin and trace mineral premix ${ }^{1)}(\%)$ & 0.50 & 0.50 \\
Total & 100.00 & 100.00 \\
Calculated composition & & \\
Metabolizable energy ${ }^{2)}\left(\mathrm{kcal} / \mathrm{kg}^{\prime}\right)$ & 2,900 & 2,700 \\
Crude protein & 21 & 18 \\
Methionine & 0.50 & 0.40 \\
Cystine & 0.36 & 0.32 \\
Lysine & 1.10 & 0.90 \\
Calcium & 0.88 & 0.86 \\
Nonphytate phosphorus & 0.39 & 0.38 \\
\hline
\end{tabular}

Stage 1: Cu $10 \mathrm{mg}\left(\mathrm{CuSO}_{4} \cdot 5 \mathrm{H}_{2} \mathrm{O}\right)$, Fe $60 \mathrm{mg}\left(\mathrm{FeSO}_{4} \cdot 7 \mathrm{H} 2 \mathrm{O}\right)$, Zn $60 \mathrm{mg}(\mathrm{ZnO}), \mathrm{Mn} 80$ $\mathrm{mg}\left(\mathrm{MnSO}_{4} \cdot \mathrm{H}_{2} \mathrm{O}\right)$, Se $0.3 \mathrm{mg}\left(\mathrm{NaSeO}_{3}\right), 10.2 \mathrm{mg}(\mathrm{KI}), \mathrm{Cr} 0.15 \mathrm{mg}\left(\mathrm{Cr}_{2} \mathrm{O}_{3}\right)$, choline chloride, 1,000 mg; vitamin $\mathrm{A} 10,000 \mathrm{IU}$ (retinyl acetate), vitamin $\mathrm{D}_{3} 3,000 \mathrm{IU}$ (cholecalciferol), vitamin E $20 \mathrm{IU}$ (DL- $\alpha$-tocopheryl acetate), vitamin $\mathrm{K}_{3} 2 \mathrm{mg}$ (menadione sodium bisulfate), thiamin $2 \mathrm{mg}$ (thiamin mononitrate), riboflavin $8 \mathrm{mg}$, pyridoxine hydrochloride $4 \mathrm{mg}$, cobalamin $0.02 \mathrm{mg}$, calcium-D-pantothenate- $20 \mathrm{mg}$, nicotinic acid $50 \mathrm{mg}$, folic acid $1 \mathrm{mg}$, biotin $0.2 \mathrm{mg}$.

Stage 2: Cu $10 \mathrm{mg}\left(\mathrm{CuSO}_{4} \cdot 5 \mathrm{H}_{2} \mathrm{O}\right)$, Fe $60 \mathrm{mg}\left(\mathrm{FeSO}_{4} \cdot 7 \mathrm{H}_{2} \mathrm{O}\right), \mathrm{Zn} 60 \mathrm{mg}(\mathrm{ZnO}), \mathrm{Mn} 80 \mathrm{mg}$ $\left(\mathrm{MnSO}_{4} \cdot \mathrm{H}_{2} \mathrm{O}\right)$, Se $0.3 \mathrm{mg}\left(\mathrm{NaSeO}_{3}\right), \mathrm{l} 0.2 \mathrm{mg}(\mathrm{KI}), \mathrm{Cr} 0.15 \mathrm{mg}\left(\mathrm{Cr}_{2} \mathrm{O}_{3}\right)$, choline chloride, $750 \mathrm{mg}$; vitamin A 8,000 IU (retinyl acetate), vitamin $\mathrm{D}_{3} 3,000 \mathrm{IU}$ (cholecalciferol), vitamin E 20 IU (DL- $\alpha$-tocopheryl acetate), vitamin $K_{3} 2 \mathrm{mg}$ (menadione sodium bisulfate), thiamin $1.5 \mathrm{mg}$ (thiamin mononitrate), riboflavin $8 \mathrm{mg}$, pyridoxine hydrochloride $3 \mathrm{mg}$, cobalamin $0.02 \mathrm{mg}$, calcium-D-pantothenate- $10 \mathrm{mg}$, nicotinic acid $50 \mathrm{mg}$, folic acid 1 $\mathrm{mg}$, biotin $0.2 \mathrm{mg}$.

1) The quantity of nutrients supplied per kilogram diet.

2) The values are calculated according to the AME of chickens (Ministry of Agriculture of China, 2004).

applied to a sire-dam model for all traits using the ASREML software [17].

$$
\mathrm{Y}_{\mathrm{ijk}}=\mu+\text { Sex }_{\mathrm{i}}+\mathrm{Hatch}_{\mathrm{j}}+\mathrm{a}_{\mathrm{k}}+\mathrm{e}_{\mathrm{ijk}}
$$

Where $Y_{\mathrm{ijk}}$ is the record of the kth duck from the ith Sex and $j$ th hatch; $\operatorname{Sex}_{\mathrm{i}}=$ fixed effect of $\operatorname{sex}(\mathrm{I}=1,2$ male/female $)$, Hatch $_{j}=$ fixed effect of hatch $(i=1,2) ; a_{k}=$ random direct additive genetic effect of individual $\mathrm{k}$, and $\mathrm{e}_{\mathrm{ijk}}=$ random residual error.

At first the variance components were estimated for each trait using bivariate analyses including the selection criteria to properly account for the effect of selection [18]. To estimate the genetic correlations between all pairs of feed efficiency growth traits, 3-trait analyses were performed, including the selection criteria as for bivariate analysis. The pedigree contained one generation. From the variance component estimations, 
the heritability of each trait $i$ was estimated as $\mathrm{h}_{i}^{2}=4 \times \sigma_{i}^{2} / \sigma^{2} \mathrm{p}_{i}$, where $\sigma^{2}{ }_{i}$ is the additive variance and $\sigma^{2} p_{i}$ is the phenotypic variance for trait $i$. Genetic correlations $\operatorname{rg}_{i j}$ between traits $i$ and $j$ were estimated as $\operatorname{rg}_{i j}=\operatorname{cov}_{i j} / \sqrt{\sigma_{i}^{2} \times \sigma_{j}^{2}}$, where $\operatorname{cov}_{i j}$ is the covariance between traits $i$ and $j$.

\section{RESULTS}

The means and standard deviations (SD) of the traits in the study are presented in Table 2. It should be noted that, for FCR and RFI, lower values indicate greater efficiency. During the test period, the average RFI was null 0 (SD, 229), the average FCR was 2.53 (SD, 0.18), and ADG was $65.59 \mathrm{~g} / \mathrm{d}$ (SD, $5.23 \mathrm{~g} / \mathrm{d}$ ). The heritability estimates for all the traits were ranged from $0.32 \pm 0.11$ for FI to $0.41 \pm 0.12$ for BW42 $2^{0.75}$. The heritability of RFI was $0.41 \pm 0.18$. The estimate of heritability for FCR $(0.38 \pm 0.15)$ was of similar magnitude as the estimate of ADG $(0.38 \pm 0.20)$. The estimate of heritability for BW was $0.39 \pm 0.12$.

Phenotypic correlations between the feed efficiencies traits are presented in Table 3. The phenotypic correlation between RFI and FCR was $0.55 \pm 0.04$; RFI was strongly correlated with FI (0.82 \pm 0.03$)$; RFI was not found to be phenotypically correlated with BW42 and ADG. The phenotypic correlation between FCR and ADG was strongly negative $(-0.80 \pm 0.04)$. The correlation was also negative between FCR and BW42 (0.65 \pm 0.02$)$. The phenotypic correlation between FCR and FI was $0.44 \pm 0.01$. ADG was strongly correlated with BW $(0.92 \pm 0.01)$. The phenotypic correlation between ADG and FI was $0.48 \pm 0.02$. The phenotypic correlation between BW and RI was $0.56 \pm 0.02$.

Table 3 shows the genetic correlations between the feed efficiency traits. The genetic correlation between RFI and FCR or FI were positive $(0.54 \pm 0.05$ and $0.77 \pm 0.17)$, but not with the ADG and the BW. FCR was negatively correlated with ADG $(0.80 \pm 0.11)$ and BW42 $(0.64 \pm 0.14)$. ADG was strongly correlated with BW42 $(0.92 \pm 0.08)$.

\section{DISCUSSION}

The FCR is a ratio trait that is subject to skewness and kurtosis as a result of the changes in the coefficient of variation of BWG (denominator) and subsequently affects SD, covariances and correlations [19]. This is due to the disproportionate fashion
Table 2. Descriptive statistics and heritability of feed efficiency parameters in Pekin duck

\begin{tabular}{lcccc}
\hline Trait & Mean & SD & Heritability & SE \\
\hline BW42 $^{0.75}(\mathrm{~g})$ & 416 & 19 & 0.41 & 0.12 \\
BW42 $(\mathrm{g})$ & 3110 & 197 & 0.39 & 0.12 \\
FI (g) & 5773 & 278 & 0.327 & 0.11 \\
FCR & 2.53 & 0.18 & 0.38 & 0.15 \\
ADG (g/d) & 65.59 & 5.23 & 0.38 & 0.20 \\
RFI & 0.00 & 229 & 0.41 & 0.18 \\
\hline
\end{tabular}

SD, standard deviations; SE, standard error; BW42 ${ }^{0.75}, 42$ th days metabolic body weight; BW42, 42th days body weight; Fl, 15 to 42 days feed intake; FCR, feed conversion ratio; $A D G$, average daily gain; $R F I$, residual feed intake.

by which selection pressure is exerted on the component traits. The RFI is a linear index the weights of the component traits in which are determined by only biological variances. The selection response based on a linear index would be higher than that of the response from a direct selection. With an understanding of the biological significance of RFI, RFI has increasingly become a preferred choice for measuring feed efficiency and is considered to be one of the target traits in animal breeding programs [20]. But in the literature on ducks the data on RFI is scant.

The heritability estimates for FCR and RFI were 0.38 and 0.41 respectively, in our study population of Pekin duck. They were within the limits of published data in beef cattle, pigs and turkeys $[5,6,8,21,22]$; selection for low RFI will improve feed efficiency with an expected correlated response in FI. Based on the genetic correlation between RFI and metabolic body weight as obtained, it could be mentioned that this would favor obtaining a lower maintenance energy requirement in ducks. In the current study, the genetic interrelationships among the feed efficiency parameters were estimated from 14 days to 42 days of feeding. Cai et al. [6] and Hoque et al. [23] have also reported a positive genetic correlation between RFI and ADG in pigs selected for low RFI, which is similar to the genetic correlation in this study. However, a lack of genetic correlation was reported in cattle and pigs $[5,9,24,25]$. In pigs, RFI is negatively correlated to dressing percentage and positively correlated with back fat thickness [5]. It is possible that the internal allocation of resources above maintenance into protein accretion and fat deposition among other animals could contribute towards the different interrelationships between factors that

Table 3. Estimates of genetic (below diagonal) and phenotypic (above diagonal) correlations for growth and feed efficiency trait in Pekin duck

\begin{tabular}{lccrrr}
\hline Traits & RFI & FCR & ADG & BW42 & FI \\
\hline RFI & & $0.55(0.04)$ & $0.00(0.02)$ & $0.00(0.01)$ & $0.82(0.03)$ \\
FCR & $0.54(0.05)$ & & $-0.80(0.04)$ & $-0.65(0.02)$ & $0.44(0.01)$ \\
ADG & $-0.05(0.23)$ & $-0.80(0.11)$ & & $0.92(0.01)$ & $0.48(0.02)$ \\
BW42 & $-0.04(0.20)$ & $-0.64(0.14)$ & $0.92(0.08)$ & & $0.56(0.02)$ \\
FI & $0.77(0.17)$ & $0.49(0.13)$ & $0.49(0.15)$ & $0.56(0.12)$ & \\
\hline
\end{tabular}

Values in the parentheses indicate standard error of correlation estimates.

$R F I$, residual feed intake; $F C R$, feed conversion ratio; $A D G$, average daily gain; BW42, 42th days body weight; $F I, 15$ to 42 days feed intake. 
affect RFI at different periods [8].

This study's conclusions and implications apply to growing ducks. The results have shown that the selection against RFI may improve the FCR trait in the young growing ducks, and their efficiencies to maintenance energy expenditures. But feed efficiency is a compound trait, and measured over a long period. Therefore, it is affected by many factors, and the genetic relationships among feed efficiency parameters are also vary with these factors.

\section{CONFLICT OF INTEREST}

We certify that there is no conflict of interest with any financial organization regarding the material discussed in the manuscript.

\section{ACKNOWLEDGMENTS}

This paper was supported by the Program of CARS-43 in China, and Program of 2011BAD28B03.

\section{REFERENCES}

1.Zhang W, Aggrey S. Genetic variation in feed utilization efficiency of meat-type chickens. World's Poult Sci J 2003;59:328-39.

2.Koch RM, Swiger L, Chambers D, Gregory K. Efficiency of feed use in beef cattle. J Anim Sci 1963;22:486-94.

3.Bordas A, Merat P. Genetic variation and phenotypic correlations of food consumption of laying hens corrected for body weight and production. Br Poult Sci 1981;22:25-33.

4.Archer JA, Pitchford WS, Hughes TE, Parnell PF. Genetic and phenotypic relationships between food intake, growth, efficiency and body composition of mice post weaning and at maturity. Anim Sci 1998;67:171-82.

5.Gilbert H, Bidanel J-P, Gruand J, et al. Genetic parameters for residual feed intake in growing pigs, with emphasis on genetic relationships with carcass and meat quality traits. J Anim Sci 2007;85:3182-8.

6.Cai W, Casey D, Dekkers J. Selection response and genetic parameters for residual feed intake in Yorkshire swine. J Anim Sci 2008;86:287-98.

7.Drouilhet L, Gilbert H, Balmisse E, et al. Genetic parameters for two selection criteria for feed efficiency in rabbits. J Anim Sci 2013;91:3121-8.

8.Aggrey SE, Karnuah AB, Sebastian B, Anthony NB. Genetic properties of feed efficiency parameters in meat-type chickens. Genet Sel Evol 2010;42:1-5.

9.Arthur P, Archer J, Johnston D, Herd R, Richardson E, Parnell P. Genetic and phenotypic variance and covariance components for feed intake, feed efficiency, and other postweaning traits in
Angus cattle. J Anim Sci 2001;79:2805-11.

10. Schenkel F, Miller S, Wilton J. Genetic parameters and breed differences for feed efficiency, growth, and body composition traits of young beef bulls. Can J Anim Sci 2004;84:177-85.

11. Cruz GD, Rodríguez-Sánchez JA, Oltjen JW, Sainz RD. Performance, residual feed intake, digestibility, carcass traits, and profitability of Angus-Hereford steers housed in individual or group pens. J Anim Sci 2010;88:324-9.

12. Durunna ON, Wang Z, Basarab JA, Okine EK, Moore SS. Phenotypic and genetic relationships among feeding behavior traits, feed intake, and residual feed intake in steers fed grower and finisher diets. J Anim Sci 2011;89:3401-9.

13. Durunna ON, Colazo MG, Ambrose DJ, Mccartney D, Baron VS, Basarab JA. Evidence of residual feed intake reranking in crossbred replacement heifers. J Anim Sci 2012;90:734-41.

14. Mrode R, Kennedy B. Genetic variation in measures of food efficiency in pigs and their genetic relationships with growth rate and backfat. Anim Prod 1993;56:225-32.

15. Le NT, Le FHN, Louveau I, Gilbert H, Gondret F. Metabolic changes and tissue responses to selection on residual feed intake in growing pigs. J Anim Sci 2012;90:4771-80.

16. SAS (Statistical Analysis System) Insitute Inc. SAS User's Guide: Version 8.12. Cary, NC, USA: SAS Institue Inc.; 1998.

17. Gilmour, AR, Gogel BJ, Cullis BR, Thompson R. ASREML User Guide. Release 3.0. Hemel Hempstead, UK: VSN International Ltd; 2009.

18. Hofer A. Variance component estimation in animal breeding: a review. J Anim Breed Genet 1998;115:247-65.

19. Atchley WR, Gaskins CT, Anderson D. Statistical properties of ratios. I. Empirical results. Syst Biol 1976;25:137-48.

20. Fan B, Lkhagvadorj S, Cai W, et al. Identification of genetic markers associated with residual feed intake and meat quality traits in the pig. Meat Sci 2010;84:645-50.

21. Aggrey SE, Karnuah AB, Sebastian B, Anthony NB. Research Genetic properties of feed efficiency parameters in meat-type chickens. Genet Sel Evol 2010;42:25.

22. Case LA, Wood BJ, Miller SP. The genetic parameters of feed efficiency and its component traits in the turkey (Meleagris gallopavo). Genet Sel Evol 2012;44:2.

23. Hoque M, Kadowaki H, Shibata T, Oikawa T, Suzuki K. Genetic parameters for measures of residual feed intake and growth traits in seven generations of Duroc pigs. Livest Sci 2009;121:45-9.

24. Herd R, Bishop S. Genetic variation in residual feed intake and its association with other production traits in British Hereford cattle. Livest Prod Sci 2000;63:111-9.

25. Arthur P, Renand G, Krauss D. Genetic and phenotypic relationships among different measures of growth and feed efficiency in young Charolais bulls. Livest Prod Sci 2001;68:131-9. 